\title{
Presented a Novel Scheme for Hysteresis Current Control by Hysteresis Current Control Grid Connected PV Three Level Inverter with LCL Filter
}

\section{Samavati $E^{*}$}

Khaje Nasir University, Yazd, Meydan Alam, Bolvar Javan Tehran, Iran

\begin{abstract}
Nowadays power quality is the most important issues in distributed power grids. Hysteresis current is one of the factors that reduce power quality in grid. This paper describes a hysteresis current controller inverter with application of a grid-connected PV system with application of LCL filter. The aim of this project is to reduce the hysteresis current magnitude and its THD by three levels PV gride connected inverter and remain in steady state inverter while reducing the switching frequency, reduces the losses. In addition, we add to this inverter, $L$ filter and next time add LCL filter. We observe the function of each of them on the hysteresis current control. In fact, reducing hysteresis current causes improves power quality and final aim of this project is to improve the power quality of distribution network. This control method provides, unity power factor, load harmonic distortion reduction and reduce hysteresis current amplitude to 2.2 A. So by this method we improved power quality of distributed grid. This system uses one of the main sources of renewable energy. In this paper we want to do a complete simulation for hysteresis current control software using MATLAB / SIMULINK and SIM POWER toolbars.
\end{abstract}

Keyword: Hysteresis; PV inverter; LCL filter; Controller; Current

\section{Introduction}

Today, the power quality of power systems is very important issue. One of the parameters affecting on lack of power quality, is flowing large hysteresis current of power transformers in the network. The hysteresis current as one of the most important phenomena of switching, has damaging impacts on the network. The most damaging effects of these currents on the network can point to the voltage sag, voltage unbalance, high current harmonics, creating resonant and fault in the performance of protective relays. Also, the hysteresis current accelerated aging and reduce the useful life of the insulation of grid transformers. It causes severe mechanical stresses between the internal components of transformers. Therefore, extensive studies have been done to reduce the inrush current transformers. We meant to avoid the detrimental effects on the transformers and network. Hysteresis modulation has been widely used for power electronic converters [1,2]. An LCL filter output for the analysis and design of PV grid-connected inverter system is done in this paper. Using three-level inverter reduces switching frequency and the losses. Simulation and experimental results are presented along with the inverter control function. The contribution of this paper is that provide a novel control method by this inverter for reducing the hysteresis current flowed in grid. These are some works that have done in topic of hysteresis current control. In reference [3], a simple digital hysteresis current control with quasiconstant switching frequency for the current control of a single-phase grid-connected inverter is proposed. The hysteresis band is cancelled, and the switching frequency is fixed by online adjusting the sampling period. In reference [4], presents a new space-vector hysteresis current control modulation for active power filters when applied to three-phase isolated neutral point systems. The space-vector-based method allows for the efficient use of zero-voltage vectors and prevents high switching frequencies caused by phase interference. In reference [5], presents a comparative study of three phase voltage source PWM boost type rectifier employing different types of hysteresis controller's namely constant hysteresis band, adaptive hysteresis band, and simplified adaptive and sinusoidal hysteresis band controllers for the input current control. In reference [6], presents the VSI based STATCOM using Hysteresis current controller for mitigating voltage sag due to sudden increase in load. As a solution for mitigation of voltage sag generally The Static Synchronous compensator is employed. In reference[7], synchronous reference frame theory controlling strategy is presented to generate reference current utilizing four-leg three-phase fourwire Distribution Static Compensator (DSTATCOM). An adaptive hysteresis band current controller is proposed to control the hysteresis bandwidth according to the modulation frequency, supply voltage, DC capacitor voltage and slope of the reference compensator current wave. In reference [8], discus a design by using power converters, injecting transformer and LCL filter connected to small system through wind turbine. But so far much work has not been done on the decreasing of the amplitude of hysteresis current. Just in reference [9] use twolevel inverter without filter to control hysteresis current but in the Result the amplitude of hysteresis current become $30 \mathrm{~A}$, but in this paper this current reduces to $2.2 \mathrm{~A}$. The aim of this paper is to reduce the hysteresis current and its effects on the network and also reduce the harmonic's load current. With The simulation results will present Hysteresis current curve with applying the presented controller. Also the inverter voltage curve is shown after applying the hysteresis current controller [10]. In continues of this paper discusses about the concept of hysteresis and the need to control it and its effects on the network. In the end, present a new scheme to control this current using a threelevel Inverter and grid-connected photovoltaic systems and explain conclusions and recommendations for the future.

\section{Hysteresis Current and Control Needs}

In normal operation the hysteresis transformer current is small percentage of the rated current. On the effect of breaker Contact of

*Corresponding author: Samavati E, Khaje Nasir University, Yazd, Meydan Alam, Bolvar Javan Tehran, Iran, Tel: 98-353-8208290; E-mail: e.samavati2010@yahoo.com

Received April 04, 2016; Accepted April 13, 2016; Published April 27, 2016

Citation: Samavati E (2016) Presented a Novel Scheme for Hysteresis Current Control by Hysteresis Current Control Grid Connected PV Three Level Inverter with LCL Filter. J Electr Electron Syst 5: 182. doi:10.4172/2332-0796.1000182

Copyright: (c) 2016 Samavati $E$. This is an open-access article distributed under the terms of the Creative Commons Attribution License, which permits unrestricted use, distribution, and reproduction in any medium, provided the original author and source are credited. 
the primary of the power transformer due to non-liner core property and existence of hysteresis in that, the currents with slope steep and high amplitude is drawn from grid. This inrush(hysteresis) currents are asymmetric, with high amplitude and has a wide harmonic spectrum include even and odd harmonics. The size of Inrush current basically depend on two factors, the point of the voltage waveform that breaker is closed and the size of residual flux in the transformer core [11]. 3-Presented scheme for hysteresis current control Operation and control of photo voltaic grid-connected inverter is recognized by simulation and we will see the amplitude of controlled hysteresis current. In Figure 1 shows the performance of photo voltaic gridconnected inverter. In this block diagram, scope 1 shows the controlled hysteresis current. Hysteresis current control is presented in the simulation and the graphically result [12].

In block diagram of this control scheme, PV source that is modelled by a DC source with amplitude of $340 \mathrm{v}$, is connected to a two-bridge three-level inverter with internal resistance of $0.3 \mathrm{ohm}$. The output current and output voltage of inverter are measured and both of them are entered the hysteresis controller block. The output of this block is controlled hysteresis current that is interred into the PV inverter. The measured output voltage and current is interred into the grid again, and this cycle continues up to the hysteresis current decreased and voltage harmonic distortion is reduced. In fact, the hysteresis current of grid is controlled by PWM method. As previously explained in this method, the hysteresis current, chooses a sinusoidal signal with a proper domain as a reference and following it upto the hysteresis current's amplitude become the same as the reference signal's amplitude. In this section we choose grid voltage's signal as a reference signal. In fact, a complete sinusoidal signal is the reference. In Figure 2 shows the grid voltage that is as the reference signal, and finally the output current of the inverter that is the controlled hysteresis current. As Figure 3 shows, the amplitude of controlled hysteresis current become to $15.5 \mathrm{~A}$.

Now add L filter to this scheme. We see that the L filter has a good performance in the Attenuation of hysteresis current's ripple. In Figure 4 shows the utilization of $\mathrm{L}$ filter in the control scheme.

In Figure 5 shows the controlled hysteresis current in this scheme, we observe that the hysteresis current is reduced to $3.5 \mathrm{~A}$. So using $\mathrm{L}$ filter in this scheme improved the hysteresis current control.

Now in this scheme we use LCL filter instead of L filter. In Figure 6 shows the PV grid connected three level inverter with LCL filter.

In Figure 7 shows the controlled hysteresis current by the above scheme, we observe that the LCL filter attenuation performance in

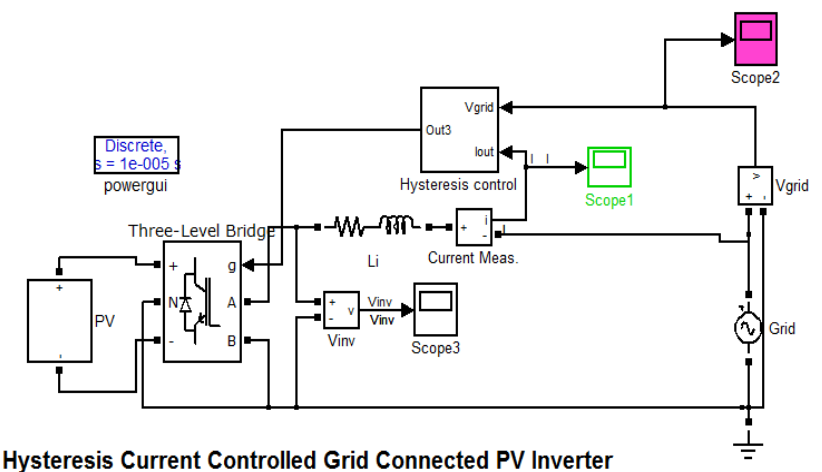

Figure 1: Grid connected PV three-level inverter.

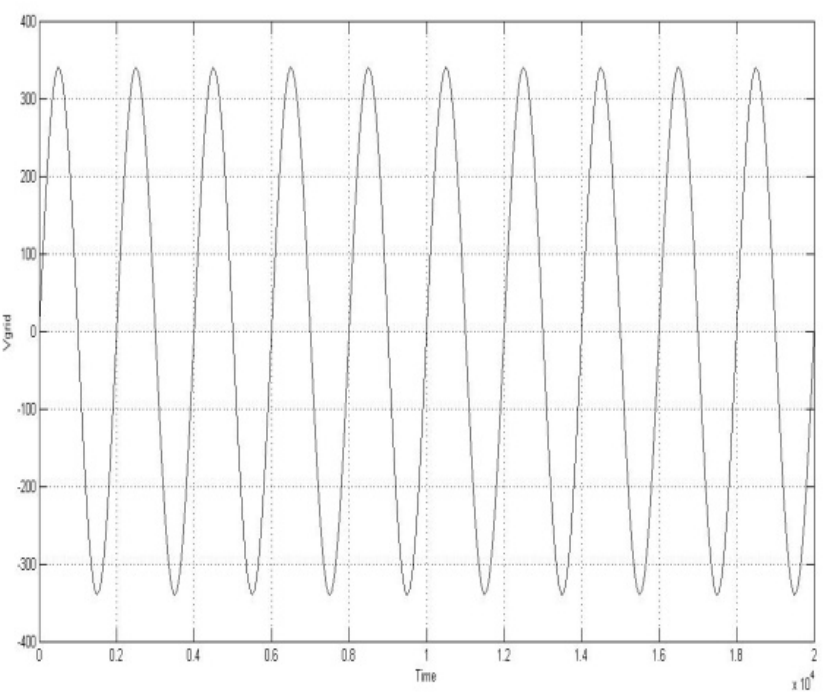

Figure 2: Voltage grid waveform.

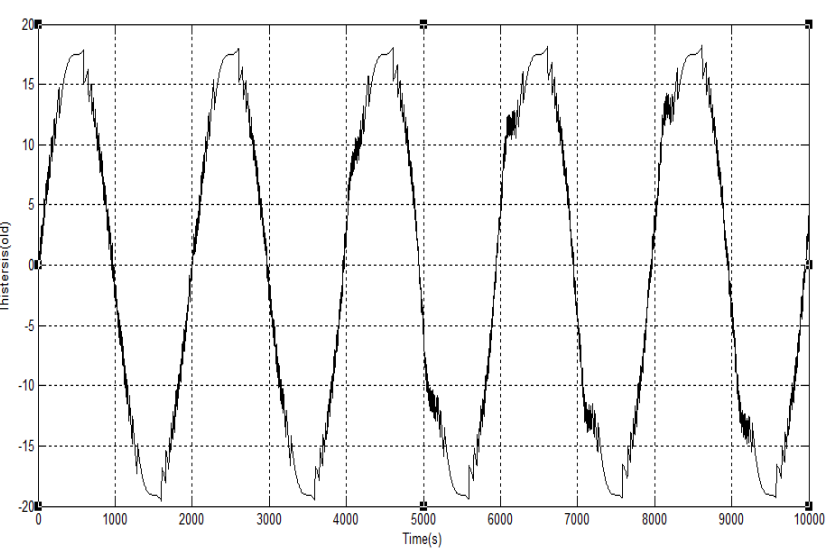

Figure 3: The controlled hysteresis current waveform.

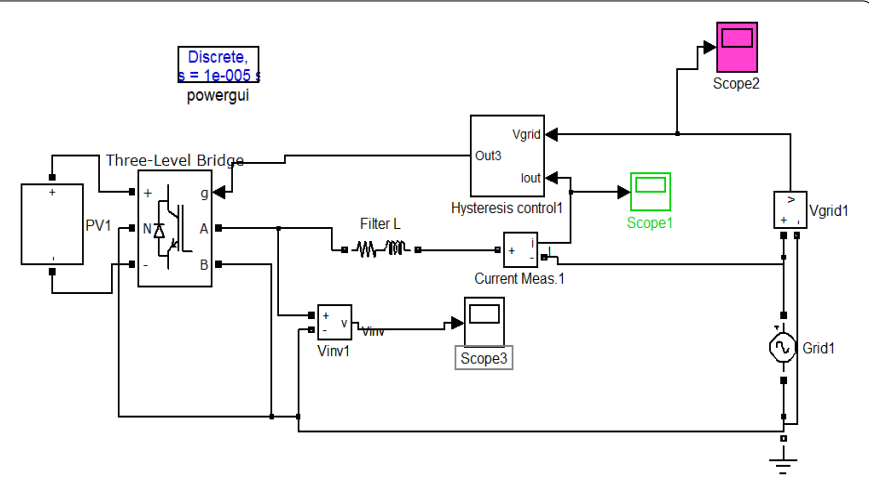

Figure 4: Utilization of $L$ filter in PV grid connected three-level inverter.

the ripple of hysteresis current, and eliminates harmonic distortion. In addition, reduces the current's amplitude to 2.2 A.But it is applied a resonant frequency to the system. Resonance is the tendency of the system to oscillate with maximum amplitude at particular frequencies that called resonant frequency. In such frequencies, oscillated energy stored in system. Therefore, small and intermittent force can cause oscillating motion with large amplitude. As we observe if we 
Citation: Samavati E (2016) Presented a Novel Scheme for Hysteresis Current Control by Hysteresis Current Control Grid Connected PV Three Level Inverter with LCL Filter. J Electr Electron Syst 5: 182. doi:10.4172/2332-0796.1000182

Page 3 of 3

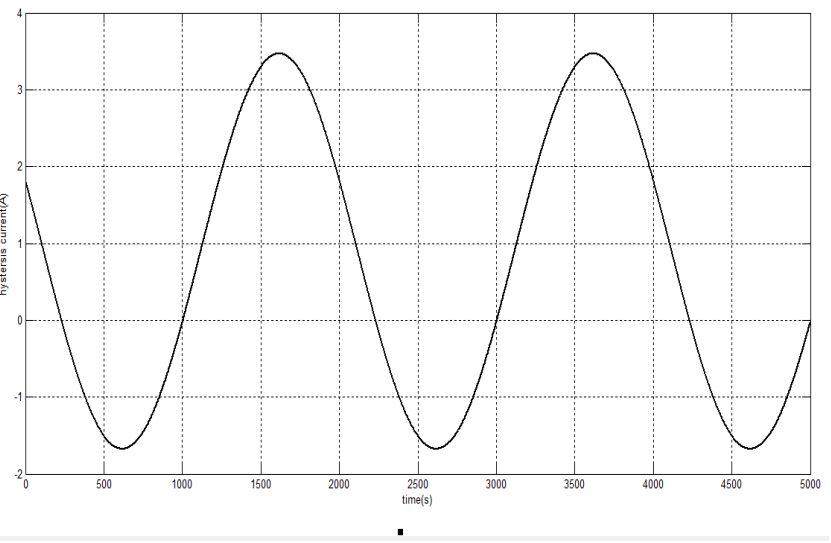

Figure 5: Controlled hysteresis current by utilization of L-filter.

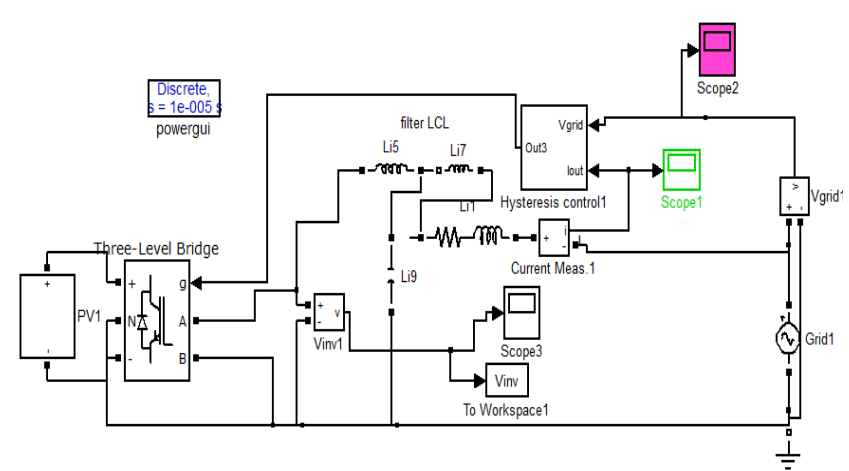

Figure 6: Utilization of LCL filter in grid connected three-level inverter.

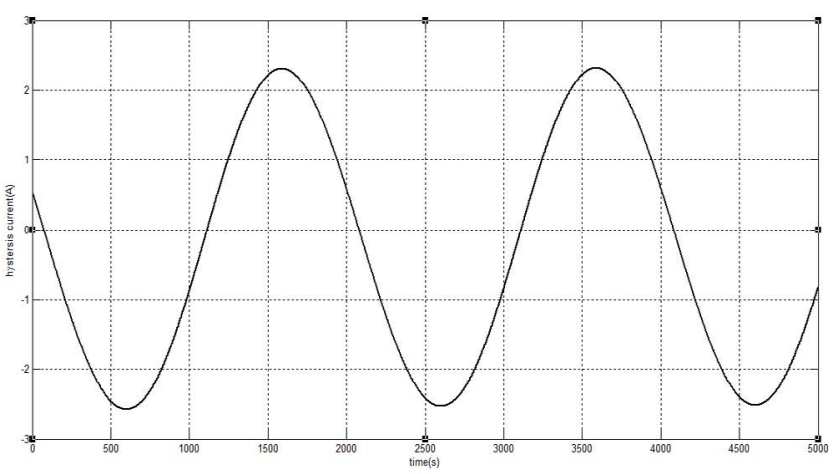

Figure 7: Controlled hysteresis current using LCL filter.

compare Figure 7 with Figure 4, by using LCL filter, obtain a complete sinusoidal hysteresis current waveform without distortion. So, the current harmonic distortion is reduced that has a great effect on improving power quality. Therefor the combination of photo voltaic grid-connected inverter and LCL filter can have a significant impact in reducing hysteresis current.

\section{Conclusion}

This paper is improved hysteresis current control by a new control scheme using PV three-level inverter. Results will cause the inverter current, follow the reference signal from the photo voltaic system and feed power grid. Also, caused the amplitude of the hysteresis current, decreases. This control strategy maintains all benefits that refer to hysteresis current control for full-bridge inverter.

The Cost of this system according to the low number of sensors that used in power equipment is very cheap. The effectiveness of this control scheme and simulation results are brought. First, in this scheme a PV three-level inverter is considered for the hysteresis current control, we see that the amplitude of the hysteresis current will be $15.5 \mathrm{~A}$. But has some Distortion current. Now use PV three-level inverter and filter L to control, we observe that the amplitude of the hysteresis current goes to $3.5 \mathrm{~A}$ and harmonic distortion reduced. If applied the PV three-level inverter and LCL filter to control the hysteresis current, the hysteresis current reduced to $2.2 \mathrm{~A}$, in addition completely removing harmonic distortion. But LCL filter is applied a little resonance to the system. Finally, with considering all the aspect concludes that PV three-level inverter filter have better efficiency in hysteresis current control.

\section{References}

1. Mokhtarpour A, Bathaee M, Shayanfar HA (2012) Power quality compensation in smart grids with a single phase upqc-dg. IEEE Trans Smart Grids (ICSG), 2nd Iranian Conference: 1-5.

2. Attanasio R, Cacciato M, Gennaro F, Scarcella G (2008) Review on singlephase pv inverters for grid-connected applications. 4th IASME/WSEAS International Conference on Energy, Environment, Ecosystems and Sustainble development: 233-238.

3. Fengjiang W, Fan F, Linsong L, Jiandong D (2015) Sampling period online adjusting-based hysteresis current control without band with constant switching frequency. Industrial Electronics, IEEE Transactions 62.

4. Fereidouni A, Masoum MAS (2015) A New space-vector hysteresis currentcontrol modulation for active power filter applications. PowerTech, IEEE Eindhoven: 1-5.

5. Suhara EM, Nandakumar M (2015) Analysis of hysteresis current contro techniques for three phase PWM rectifiers. Signal Processing, Informatics, Communication and Energy Systems (SPICES), IEEE International Conference.

6. Lata L, Elango MK (2015) Hysteresis current controller for STATCOM under voltage sag, Advanced Computing and Communication Systems, International Conference: $1-4$

7. Rohani A, Joorabian M, Rahimi S (2014) Power quality improvement in threephase four-wire distribution systems by DSTATCOM and using adaptive hysteresis band current controller. Electrical Engineering (ICEE), 22nd Iranian Conference.

8. Sonavane SR, Jadhav HT (2015) Stand-alone wind energy generation system using hysteresis current control method for SCIM, Electrical, Electronics, Signals, Communication and Optimization (EESCO), International Conference: 1-6.

9. Haiyang Z, Xiu Y (2011) Simulation of two-level photovoltaic grid-connected system based on current control of hysteresis band. Power and energy engineering conference.

10. Baekhoej KS, Pedersen JK, Blaabjerg F (2005) A Review of single-phase gridconnected inverters for photovoltaic modules, IEEE transactions on industry applications 41: 1292-1306.

11. Munir S, Li YW (2013) Residential distribution system harmonic compensation using pv interfacing inverter, IEEE transactions on smart grid 4: 1949-3053.

12. Diab H, El-Helw $\mathrm{H}$, Talaat $\mathrm{H}$ (2012) Intelligent maximum power tracking and inverter hysteresis current control of grid-connected pv systems. 